\title{
BMJ Open Prospective cohort study of water immersion for labour and birth compared with standard care in an Irish maternity setting
}

\author{
Paula L Barry, ${ }^{1}$ Lean E McMahon, ${ }^{2}$ Ruth AM Banks, ${ }^{1}$ Ann M Fergus, ${ }^{1}$ \\ Deirdre J Murphy (1) ${ }^{3,4}$
}

To cite: Barry PL, McMahon LE, Banks RAM, et al. Prospective cohort study of water immersion for labour and birth compared with standard care in an Irish maternity setting. BMJ Open 2020;10:e038080. doi:10.1136/ bmjopen-2020-038080

- Prepublication history for this paper is available online. To view these files, please visit the journal online (http://dx.doi. org/10.1136/bmjopen-2020038080).

Received 29 February 2020 Revised 10 0ctober 2020 Accepted 20 November 2020

Check for updates

(c) Author(s) (or their employer(s)) 2020. Re-use permitted under CC BY-NC. No commercial re-use. See rights and permissions. Published by BMJ.

${ }^{1}$ Midwifery, Coombe Women and Infants University Hospital, Dublin, Ireland

${ }^{2}$ National Clinical Programme for Obstetrics \& Gynaecology/ National Women \& Infants Health Programme, Coombe Women's Hospital, Dublin, Ireland ${ }^{3}$ Obstetrics \& Gynaecology, Trinity College Dublin, Dublin, Ireland

${ }^{4}$ Obstetrics, Coombe Women and Infants University Hospital, Dublin, Ireland

Correspondence to Professor Deirdre J Murphy; MURPHYD4@tcd.ie

\section{ABSTRACT}

Objective To examine the birth outcomes for women and babies following water immersion for labour only, or for labour and birth.

Design Prospective cohort study.

Setting Maternity hospital, Ireland, 2016-2019.

Participants A cohort of 190 low-risk women who used water immersion; 100 gave birth in water and 90 laboured only in water. A control group of 190 low-risk women who received standard care.

Methods Logistic regression analyses examined associations between water immersion and birth outcomes adjusting for confounders. A validated Childbirth Experience Questionnaire was completed.

Main outcome measures Perineal tears, obstetric anal sphincter injuries (OASI), postpartum haemorrhage (PPH), neonatal unit admissions (NNU), breastfeeding and birth experiences.

Results Compared with standard care, women who chose water immersion had no significant difference in perineal tears $(71.4 \%$ vs $71.4 \%$, adj OR $0.83 ; 95 \% \mathrm{Cl} 0.49$ to $1.39)$ or in OASI (3.3\% vs $3.8 \%$, adj OR $0.91 ; 0.26-2.97)$. Women who chose water immersion were more likely to have a PPH $\geq 500 \mathrm{~mL}$ (10.5\% vs $3.7 \%$, adj OR $2.60 ; 95 \%$ $\mathrm{Cl} 1.03$ to 6.57), and to exclusively breastfeed at discharge (71.1\% vs $45.8 \%$, adj OR 2.59; 95\% Cl 1.66 to 4.05 ). There was no significant difference in NNU admissions (3.7\% vs 3.2\%, adj OR 1.06; 95\% Cl 0.33 to 3.42). Women who gave birth in water were no more likely than women who used water for labour only to require perineal suturing (64\% vs $80.5 \%$, adj OR $0.63 ; 95 \% \mathrm{Cl} 0.30$ to 1.33 ), to experience $\mathrm{OASI}(3.0 \%$ vs $3.7 \%$, adj OR $1.41 ; 95 \% \mathrm{Cl} 0.23$ to 8.79 ) or PPH (8.0\% vs $13.3 \%$, adj OR $0.73 ; 95 \% \mathrm{Cl} 0.26$ to 2.09 ). Women using water immersion reported more positive memories than women receiving standard care $(p<0.01)$.

Conclusions Women choosing water immersion for labour or birth were no more likely to experience adverse birth outcomes than women receiving standard care and rated their birth experiences more highly.

\section{INTRODUCTION}

The management of childbirth has become increasingly risk averse worldwide, with the primary focus being on prevention
Strengths and limitations of this study

- This study had a prospective design with clearly defined inclusion criteria and an appropriately selected comparison group.

- Quantitative and qualitative data were collected addressing the spectrum of important outcomes including maternal and perinatal morbidity, and the woman's birth experience.

- A novel aspect of the study was the use of a research framework to support organisational change in the context of resistance to a less medicalised approach to childbirth.

- A large-scale randomised controlled trial would provide a more robust answer to the research question but is likely to be challenging.

of perinatal and maternal morbidity and mortality irrespective of risk status. ${ }^{12}$ This applies to the Republic of Ireland (ROI) where maternity care is predominantly obstetric led and hospital based, resulting in birth becoming a medical event rather than a normal physiological process. ${ }^{3}$ Despite the evidence supporting a less medicalised and more individualised approach, ${ }^{4-6}$ including use of water immersion (WI) for labour and birth, ${ }^{7-10}$ introducing change in obstetric-led environments has been challenging. However, there is an increasing drive in recent years from service users, researchers and policy makers to embrace a more physiological approach to labour and birth, recognising the potential benefits in terms of safe, high quality care that offers women choice and an enhanced birth experience. ${ }^{11-15}$

In 2011, the Coombe Women and Infants University Hospital ('the Coombe'), a university teaching hospital with over 8000 births per annum, introduced a midwifery-led model of care for low-risk women as recommended by research evidence. ${ }^{416} 17$ WI was 
debated as an option to offer women an alternative more physiological approach to labour and birth. A pool room was opened on the labour ward in 2013 and a water birth (WB) service commenced in 2014. Of the 19 maternity units in the ROI, five have a birthing pool but the Coombe is currently the only unit offering women the option of WB. WB has a short history in the ROI. Two midwifery-led units were established in 2004 in the North East of the country, both offering WI for labour and birth. Tragically, in 2006, a baby died in one of these units following a WB. As a result, WB ceased entirely in the ROI. In 2009, the Health Service Executive ${ }^{18}$ published a memorandum that removed the 'WB ban', but WB has been slow to re-establish nationally.

Between March 2013 and September 2015, 230 women used the pool at the Coombe and of these, 62 had a WB. An internal audit conducted at the hospital demonstrated high satisfaction rates among pool users and a reduction in epidural and caesarean section rates in women choosing to use the pool. However, the audit also demonstrated a higher than expected incidence of obstetric anal sphincter injury (OASI) following WB $(8.1 \%)$, compared with the hospital's OASI rate of $2.2 \%$ at the time. Potential hypotheses to explain this difference included inappropriate case selection, midwives' level of WB experience, the 'hands off' WB technique, or just simply a coincidental series of cases attributable to 'bad luck'. The initial response from hospital management was to abandon WB and offer WI for labour only, in keeping with other maternity units nationally. However, women and midwives were beginning to embrace WB, and reverting to WI for labour only was regarded by many as a retrograde step. An interdisciplinary working group was formed at the hospital to examine the WB service. Following extensive discussion (including approval by the Hospital Board of Management), it was agreed that WB would be offered exclusively in the context of an enhanced midwifery professional education programme and a clinical research framework. Hence, the rationale for this research study.

\section{METHODS}

\section{Study design and participants}

The study was conducted at a large tertiary referral maternity hospital in Dublin, Ireland, with over 8000 births per year. Recruitment began in January 2016 and was completed in January 2019. A prospective observational study was chosen as it was felt that a randomised controlled trial (RCT) would not be feasible for two reasons. First, WI for labour and birth is strongly preference driven by women attending maternity hospitals and the researchers believed that it would be difficult to recruit women, half of whom would be denied the choice of pool use regardless of their suitability. Second, a meaningful RCT would require a large number of study participants. The researchers believed this would be unachievable in an acceptable timeframe with a single site and only one pool.
Women recruited to the study were cared for as per local evidence-based clinical guidelines. Definitions used were as follows: WI-use of the pool for either labour only or for labour and birth. Water labour (WL) - a woman used the pool for labour only, exiting and giving birth on 'land'. WB-the baby was born totally submerged under water and then brought immediately and gently to the surface. ${ }^{10}$ Standard care-a woman laboured and gave birth on 'land'. Standard care included two hourly vaginal examinations, a partogram action line for use of oxytocin, frequent use of cardiotocography and active management of the third stage of labour.

As recommended by Burns et $a l,{ }^{10}$ the Coombe pool is large enough for a woman to adopt different positions in labour and deep enough for the water level to cover the woman's abdomen when seated. Women were eligible to participate in the study if they were healthy, with an uncomplicated pregnancy and no medical, surgical or obstetrical risk factors. The study was based on the following inclusion criteria; women had to present at term, (between $37^{+0}$ and $41^{+6}$ weeks gestation) with a singleton fetus and cephalic presentation, be in spontaneous labour and contracting regularly. Women $<18$ years of age, with body mass index (BMI) $>30 \mathrm{~kg} / \mathrm{m}^{2}$ and/or with maternal or fetal concerns were excluded from the study. Potentially eligible participants were given information about the study during the antenatal period. Women fulfilling the criteria, who expressed a wish to use the pool were asked to sign a consent form which needed to be completed more than 24 hours before they presented in labour. Completed forms were filed in the woman's maternity notes. When these women presented in spontaneous labour, they were assessed by the midwife prior to admission to the labour ward. If labour was confirmed, the study inclusion criteria were met and the pool was available, the women were offered the pool. For each woman recruited to the WI cohort, the next consecutive woman of the same parity who presented in labour, was eligible for pool use but did not wish to avail of the service, was recruited to the control group. Women in all groups, WI and control, gave written consent to use of their data for research purposes and completed the Childbirth Experience Questionnaire (CEQ). The control group received standard labour care.

Background demographic, obstetric and medical data, and maternal and perinatal outcomes were collected for all participants. Women's birth experiences were captured prior to discharge by asking women to complete a CEQ. The CEQ was an adapted version of a Swedish validated CEQ instrument, ${ }^{19}$ which was designed to record women's experiences of labour and birth. It comprised 21 questions/statements designed to assess four domains of childbirth experiences: women's own capacity, professional support, perceived safety and participation.

\section{Sample size}

A sample size calculation was performed based on the OASI data from the initial audit, where 62 women had 
a WB with an OASI rate of $8.1 \%$ and the standard care OASI rate was $2.2 \%$. We aimed to recruit until 100 women had given birth in water and anticipated at least a similar number who would use WI for labour only. In addition, we aimed to recruit women who chose standard care but were eligible for WI at a rate of 1:1 for the total WI population (labour only and birth in water). A sample size of 400 women in total (200 WI and 200 controls) could detect a difference of $6 \%$ in OASI with $80 \%$ power at the $5 \%$ significance level assuming a complication rate of $2 \%$ in the standard care group and $8 \%$ in the WB group. The study sample included all women who used the pool during the study time period, that is, $100 \%$.

\section{Statistical analysis}

The analyses were performed using the SPSS V.25.0. ${ }^{20}$ The plan of analysis is presented in four stages. First, descriptive statistics were generated for sociodemographic, clinical and obstetric characteristics of women who used WI for labour only or for labour and birth, and women who received standard care. Univariable logistic regression analyses were performed to measure the association between WI and maternal characteristics (WI vs no immersion, and WB vs labour in water only). Second, univariable analysis was performed to measure the associations between WI and labour events. Third, univariable and multivariable logistic regression analyses were performed to measure the associations between WI and birth outcomes for mothers and babies. Multivariable stepwise logistic regression analyses adjusted for baseline differences between the groups. Potential confounding factors included maternal age, BMI, marital status, maternal occupation, parity, smoking, midwife-led care, and birth weight. These potential confounding factors for birth outcomes were chosen because of their known or potential association with mode of birth and adverse birth-related outcomes. Finally, subgroup analyses explored birth outcomes in relation to nulliparity. Results are reported as proportions, ORs, and 95\% CIs. Women's experiences were captured via the CEQ with responses coded and scored as per Dencker et al. ${ }^{19}$ Where descriptive analyses were performed, $p$ values were reported with significance at $\mathrm{p}<0.05$.

\section{Patient and public involvement}

An initial pilot phase was completed, which helped inform the design of the main study and the recruitment procedures. Recruited women were asked to provide feedback on how they were approached, the timing of recruitment and the consent procedures. Additional insights were provided by women attending antenatal birth education classes and the lay members of the institutional research ethics committee, particularly with drafting of the patient information leaflet.

\section{RESULTS}

The study comprised 380 low-risk women, with 190 women each in the WI and standard care (control) groups. Table 1 shows the baseline characteristics of the study participants based on univariable descriptive analysis. Just over half the women in each cohort $(55.3 \%)$ were nulliparous. Of the 190 women who chose WI, 100 gave birth in water (WB) and 90 used water for labour only (WL), leaving the pool to give birth. Compared with standard care, women in the WI cohort were more likely to be older ( $>35$ years) $(23.2 \%$ vs $14.7 \%$, OR $1.74,95 \%$ CI 1.03 to 2.94), of higher socioeconomic status (professional/manager) (48.9\% vs $28.4 \%$, OR $2.4295 \%$ CI 1.58 to 3.69$)$, and married or cohabiting $(90.0 \%$ vs $78.9 \%$, OR $2.40,95 \%$ CI 1.33 to 4.32 ). They were less likely to be current smokers $(2.1 \%$ vs $8.4 \%$, OR $0.23,95 \%$ CI 0.08 to 0.71$)$ or overweight (BMI $\left.25-30 \mathrm{~kg} / \mathrm{m}^{2}\right)(21.6 \%$ vs $37.9 \%$, OR $0.45,95 \%$ CI 0.29 to 0.71$)$. Women in the WI cohort were more likely to have midwife-led care $(67.9 \%$ vs $41.1 \%$, OR $3.03,95 \%$ CI 2.00 to 4.62 ) and attend antenatal classes $(54.2 \%$ vs $41.6 \%$, OR $1.66,95 \%$ CI 1.11 to $2.50)$. Women who gave birth in water were less likely to be nulliparous than women who used water for labour only $(39.0 \%$ vs $73.3 \%$, OR $0.23,95 \%$ CI 0.13 to 0.43$)$. These factors are important for the multivariable logistic regression analyses.

Table 2 shows the labour outcomes for mothers and babies in the study. The spontaneous vaginal birth (SVB) rate was $84.7 \%$ among the WI cohort and $72.6 \%$ among the standard care group. By comparison with the overall hospital SVB rate of $52.0 \%{ }^{21}$ and National rate of $51.0 \%,{ }^{22}$ our rates were high. Compared with women in the Control group, women in the WI group were less likely to use epidural analgesia ( $15.9 \%$ vs $48.9 \%$, OR 0.20 , $95 \%$ CI 0.12 to 0.32 ) or to require operative vaginal birth (OVB) by vacuum or forceps $(11.1 \%$ vs $24.7 \%$, OR 0.38 , $95 \%$ CI 0.22 to 9.67$)$. Women in the WI group were more likely to have a physiological third stage of labour $(28.9 \%$ vs $4.7 \%$, OR 8.19 ; $95 \%$ CI 3.91 to 17.16 ) and had more than a two-fold higher incidence of high birth weight babies $(>4.0 \mathrm{~kg})(13.7 \%$ vs $5.3 \%$, OR $2.85,95 \%$ CI 1.34 to 6.10). Comparing the two groups of women in the WI cohort, women who gave birth in water were more likely to have a physiological third stage $(48.0 \%$ vs $7.8 \%$, OR $10.95,95 \%$ CI 4.61 to 26.01 ) and a third stage duration $>30$ min (27.0\% vs $3.3 \%$, OR 10.73 ; $95 \%$ CI 3.13 to 36.80$)$ compared with women who used water for labour only.

The results of multivariable analyses of birth outcomes for mothers and babies is shown in table 3, with associations adjusted for maternal age, maternal occupation, marital status, current smoking status, BMI, midwife-led care, nulliparity and birth weight. The incidence of perineal tears requiring suturing was the same in the WI and standard care cohorts $(71.4 \%)$. There was no significant difference even after adjusting for confounding factors. Similarly, there was no significant difference in the incidence of OASI between women in the WI and standard care cohorts. Women in the WI group had an increased 


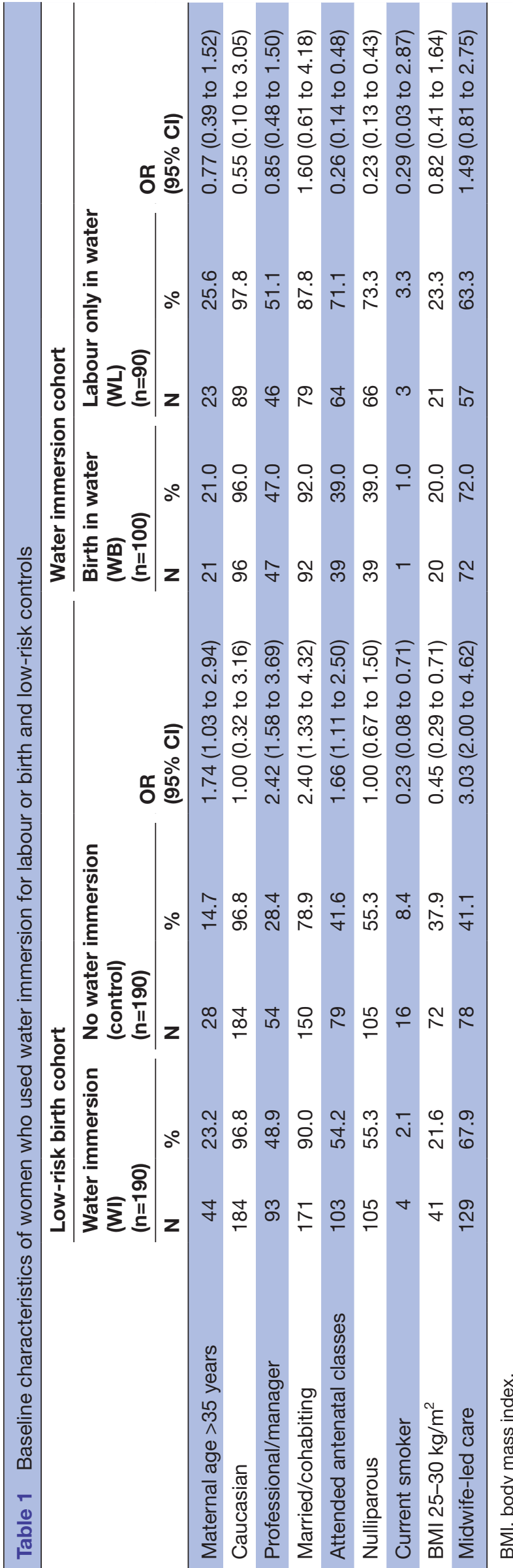

adjusted OR for postpartum haemorrhage (PPH) $\geq 500$ $\mathrm{mL}(10.5 \%$ vs $3.7 \%$, adj OR 2.60, 95\% CI 1.03 to 6.57$)$. In this group, five women (2.6\%) were admitted for High Dependency Unit (HDU) care, three following WB and two following WL. Of these, three required one or two units of blood transfused, two women following WB and one following $\mathrm{WL}$ only. All were discharged from HDU care within 12 hours. There was no significant difference in rates of $\mathrm{PPH} \geq 1000 \mathrm{~mL}$.

Adverse neonatal outcomes were uncommon in this study, with no significant difference between the groups in admissions to the neonatal unit (NNU) $(3.7 \%$ vs $3.2 \%$, adj OR 1.06; 95\% CI 0.33 to 3.42). Breastfeeding initiation and exclusive breastfeeding at discharge were higher among women in the WI cohort than the standard care group (adj OR 2.69, 95\% CI 1.45 to 4.98; and adj OR 2.59, $95 \%$ CI 1.66 to 4.05 , respectively).

Maternal and neonatal outcomes were very similar in the WB and WI for labour only groups. There was no significant difference in the incidence of OASI $(3.0 \%$ vs $3.7 \%)$. There was a lower incidence of perineal suturing in the WB group ( $64 \%$ vs $80.5 \%$, OR $0.43 ; 95 \%$ CI 0.22 to 0.85 ), but this did not persist with the adjusted model. Comparing women in the two WI groups, there were no significant differences in PPH or admissions to HDU. There were two episodes of cord avulsion 'snap' in the study, one following a WB and the other in the WL group. Neither baby required transfer to the NNU.

Table 4 shows the results for nulliparous women in the study. Among nulliparous women, WI compared with standard care was associated with significantly lower use of epidural analgesia $(24.8 \%$ vs $62.9 \%$, adj OR $0.20,95 \%$ CI 0.11 to 0.37$)$, higher incidence of SVB $(73.3 \%$ vs $50.5 \%$, adj OR 2.89, 95\% CI 1.57 to 5.34) and exclusive breast feeding at discharge $(61.9 \%$ vs $40.0 \%$, adj OR $2.14,95 \%$ CI 1.20 to 3.83 ). There were no significant differences in the incidence of perineal tears requiring suturing or the incidence of OASI.

The CEQ demonstrated that, compared with women receiving standard care, women in the WI cohort rated their birth experiences more highly across domains (table 5). Overall, women in the WI cohort reported having more positive $(\mathrm{p}<0.001)$ and less negative memories $(\mathrm{p}=0.002)$ of their birth experience than women in the standard care cohort. Women in the WI cohort scored higher for 'feeling capable' $(\mathrm{p}=0.006)$, 'feeling strong' $(\mathrm{p}=0.002)$ and 'feeling in control' $(\mathrm{p}=0.017)$. They also reported having freedom of movement $(\mathrm{p}<0.001)$ and autonomy over their birth position $(\mathrm{p}<0.001)$. Comparing women in the two WI groups, women who had a WB reported feeling less pain $(p=0.022)$ and feeling more secure $(p=0.038)$ than those who only laboured in water and gave birth 'on land'. 


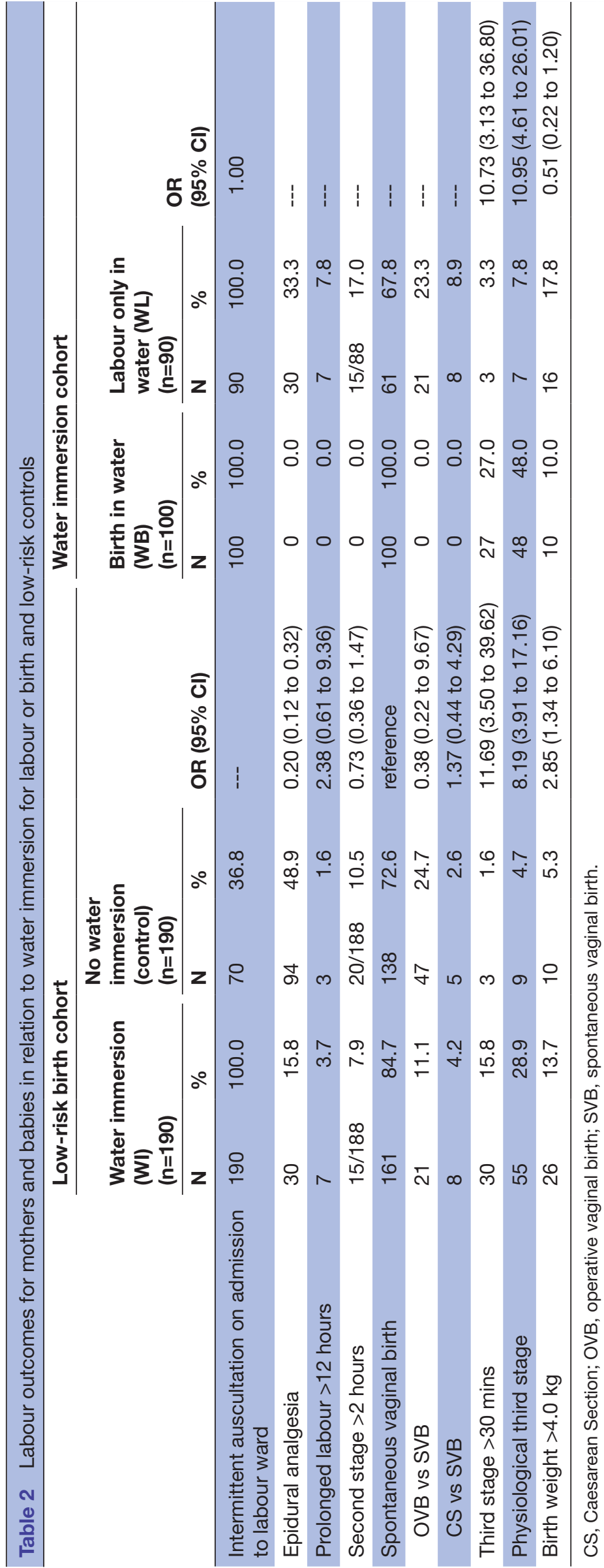




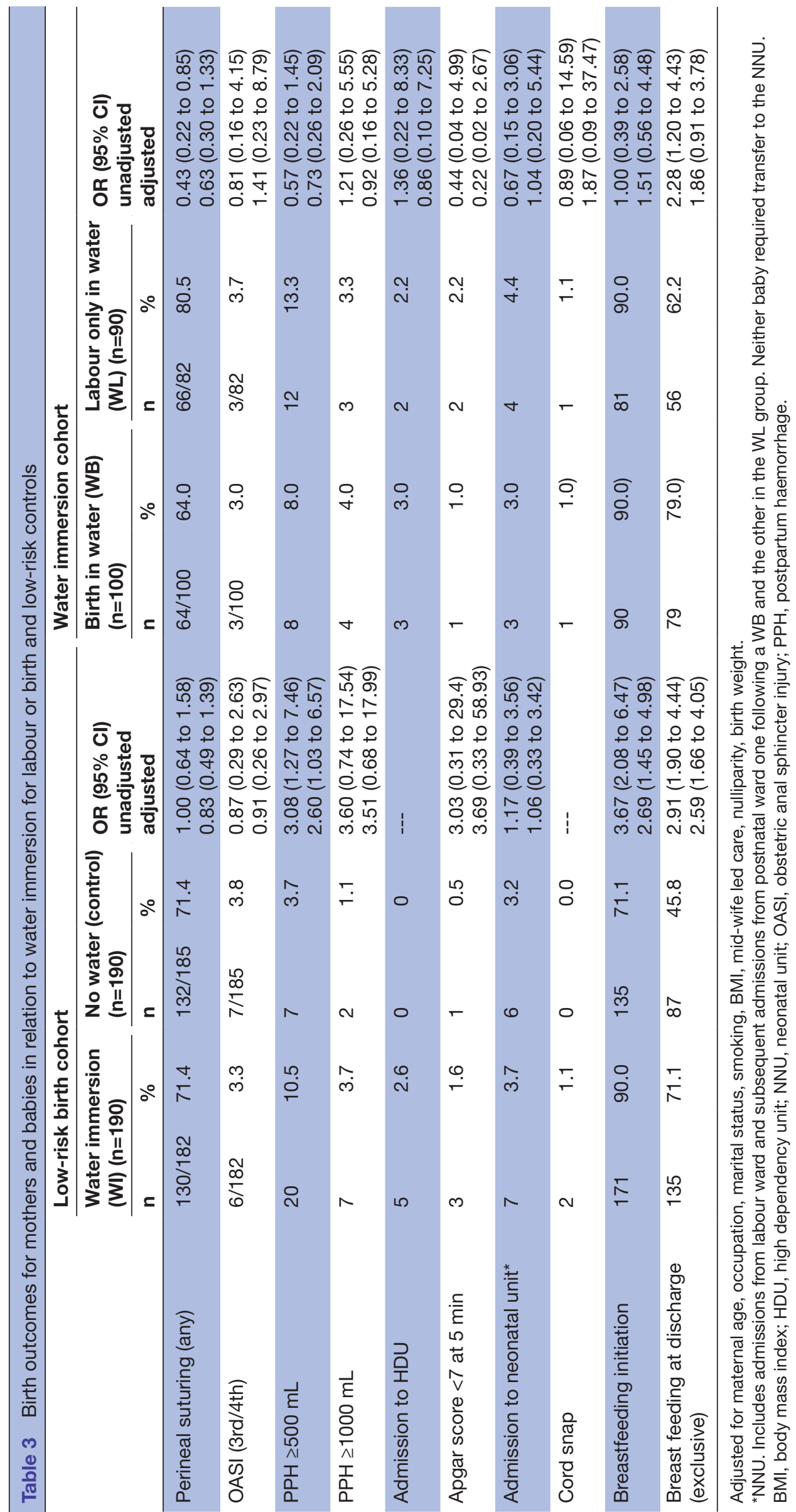


Table 4 Labour and birth outcomes for nulliparous women in relation to water immersion for labour or birth and low-risk controls

\begin{tabular}{|c|c|c|c|c|c|c|c|c|c|c|}
\hline & \multicolumn{5}{|c|}{ Low-risk birth cohort } & \multicolumn{5}{|c|}{ Water immersion cohort } \\
\hline & \multicolumn{2}{|c|}{$\begin{array}{l}\text { Water } \\
\text { immersion (WI) } \\
(n=105)\end{array}$} & \multicolumn{2}{|c|}{$\begin{array}{l}\text { No water } \\
\text { (control) }(n=105)\end{array}$} & \multirow{2}{*}{$\begin{array}{l}\text { OR }(95 \% \mathrm{Cl}) \\
\text { unadjusted } \\
\text { adjusted* }^{*}\end{array}$} & \multicolumn{2}{|c|}{$\begin{array}{l}\text { Birth in water } \\
\text { (WB) } \\
\text { (n=39) }\end{array}$} & \multicolumn{2}{|c|}{$\begin{array}{l}\text { Labour only in } \\
\text { water (WL) } \\
(\mathrm{n}=66)\end{array}$} & \multirow{2}{*}{$\begin{array}{l}\text { OR }(95 \% \mathrm{Cl}) \\
\text { unadjusted } \\
\text { adjusted* }\end{array}$} \\
\hline & $\mathbf{n}$ & $\%$ & $\mathbf{n}$ & $\%$ & & $\mathbf{n}$ & $\%$ & $\mathbf{n}$ & $\%$ & \\
\hline Epidural analgesia & 26 & 24.8 & 66 & 62.9 & $\begin{array}{l}0.19(0.11 \text { to } \\
0.35) \\
0.20(0.11 \text { to } \\
0.37)\end{array}$ & 0 & 0.0 & 26 & 39.4 & --- \\
\hline Spontaneous vaginal birth & 77 & 73.3 & 53 & 50.5 & $\begin{array}{l}2.70(1.52 \text { to } \\
4.81) \\
2.89(1.57 \text { to } \\
5.34)\end{array}$ & 39 & 100.0 & 38 & 57.6 & --- \\
\hline Perineal suturing (any) & $78 / 97$ & 80.4 & $89 / 100$ & 89.0 & $\begin{array}{l}0.51(0.23 \text { to } \\
1.13) \\
0.48(0.21 \text { to } \\
1.12)\end{array}$ & $30 / 39$ & 76.9 & $48 / 58$ & 82.8 & $\begin{array}{l}0.69(0.25 \text { to } \\
1.91) \\
0.71(0.25 \text { to } \\
1.98)\end{array}$ \\
\hline $\mathrm{PPH} \geq 500 \mathrm{~mL}$ & 16 & 15.2 & 6 & 5.7 & $\begin{array}{l}2.97(1.11 \text { to } \\
7.91) \\
2.35(0.85 \text { to } \\
6.47)\end{array}$ & 5 & 12.8 & 11 & 16.7 & $\begin{array}{l}0.74(0.24 \text { to } \\
2.35) \\
0.76(0.24 \text { to } \\
2.44)\end{array}$ \\
\hline $\mathrm{PPH} \geq 1000 \mathrm{~mL}$ & 3 & 2.9 & 2 & 1.9 & $\begin{array}{l}1.52(0.25 \text { to } \\
9.26) \\
1.20(0.19 \text { to } \\
7.64)\end{array}$ & 1 & 2.6 & 2 & 3.0 & $\begin{array}{l}0.88(0.08 \text { to } \\
10.02) \\
0.59(0.05 \text { to } \\
6.97)\end{array}$ \\
\hline $\begin{array}{l}\text { Breast feeding at discharge } \\
\text { (exclusive) }\end{array}$ & 65 & 61.9 & 42 & 40.0 & $\begin{array}{l}2.44(1.40 \text { to } \\
4.24) \\
2.14(1.20 \text { to } \\
3.83)\end{array}$ & 28 & 71.8 & 37 & 56.1 & $\begin{array}{l}2.00(0.85 \text { to } \\
4.67) \\
2.00(0.84 \text { to } \\
4.74)\end{array}$ \\
\hline
\end{tabular}

*Adjusted for maternal age, occupation, marital status, smoking, BMI, mid-wife led care, birth weight.

$\mathrm{BMI}$, body mass index; HDU, high dependency unit; OASI, obstetric anal sphincter injury; PPH, postpartum haemorrhage.

\section{DISCUSSION}

\section{Summary of main findings}

In this study of low-risk women we found that women who were older, of higher social status, married/cohabiting and healthier in terms of BMI and smoking behaviour were more likely to choose WI for labour and/or birth. Use of WI compared with standard care was associated with less epidural usage and a lower incidence of OVB. Use of WI for labour or birth did not increase the likelihood of perineal tearing or OASI but the incidence of PPH $(\geq 500 \mathrm{~mL})$ was higher. The rate of major $\mathrm{PPH}$ $(\geq 1000 \mathrm{~mL})$ was not significantly different, although the numbers are small. Neonatal complications were uncommon following use of WI for labour or birth and were similar to standard care. Exclusive breastfeeding rates at hospital discharge were higher for WI, particularly for women who had a WB, as was maternal satisfaction with the birth experience.

\section{Strengths and limitation of the study}

Strengths of this study include its prospective design, complete data collection, and recruitment of an 
Table 5 Women's experiences according to four domains: sense of own capacity, receipt of professional support, perceived sense of safety and participation/engagement (agree/strongly agree with statements, unless otherwise stated†)ł

\begin{tabular}{|c|c|c|c|c|c|c|}
\hline & \multicolumn{3}{|c|}{ Low-risk birth cohort } & \multicolumn{3}{|c|}{ Water Immersion cohort } \\
\hline & \multirow{2}{*}{$\begin{array}{l}\begin{array}{l}\text { Water immersion } \\
(\mathrm{WI})\end{array} \\
(\mathrm{N}=160) \\
\mathrm{N}(\%)\end{array}$} & \multicolumn{2}{|l|}{$\begin{array}{l}\text { No water } \\
\text { immersion } \\
\text { (control) }\end{array}$} & \multirow{2}{*}{$\begin{array}{l}\text { Birth in water } \\
\text { (WB) } \\
(\mathrm{N}=89) \\
\mathrm{N}(\%)\end{array}$} & \multicolumn{2}{|l|}{$\begin{array}{l}\text { Labour only in } \\
\text { water (WL) }\end{array}$} \\
\hline & & $\begin{array}{l}(\mathrm{N}=135) \\
\mathrm{N}(\%)\end{array}$ & $\begin{array}{l}\text { Sig. }(P \\
\text { value) }\end{array}$ & & $\begin{array}{l}(\mathrm{N}=71) \\
\mathrm{N}(\%)\end{array}$ & $\begin{array}{l}\text { Sig. }(\mathbf{P} \\
\text { value) }\end{array}$ \\
\hline \multicolumn{7}{|c|}{ 1. Sense of own capacity } \\
\hline Felt capable & 144/159 (90.6\%) & 107/135 (79.3\%) & $0.006^{\star *}$ & $85 / 89(95.5 \%)$ & $59 / 70(84.3 \%)$ & $0.016^{*}$ \\
\hline Felt strong & $142 / 160(88.8 \%)$ & $101 / 135(74.8 \%)$ & $0.002^{* *}$ & $84 / 89(94.4 \%)$ & $58 / 71(81.7 \%)$ & $0.012^{*}$ \\
\hline I handled situation well & 154/159 (96.9\%) & $118 / 135(87.4 \%)$ & $0.001^{* *}$ & $86 / 89(96.6 \%)$ & $68 / 70(97.1 \%)$ & 0.854 \\
\hline Felt tired & $96 / 160(60.0 \%)$ & $100 / 135(74.1 \%)$ & $0.011^{*}$ & $42 / 89(47.2 \%)$ & $54 / 71(76.1 \%)$ & $<0.001^{*}$ \\
\hline $\begin{array}{l}\text { Labour went as I } \\
\text { expected }\end{array}$ & $123 / 156(78.8 \%)$ & 95/135 (70.4\%) & 0.096 & $77 / 87$ (88.5\%) & $46 / 69(66.7 \%)$ & $0.001^{* \star}$ \\
\hline Felt happy & $117 / 159(73.6 \%)$ & $82 / 135(60.7 \%)$ & $0.019^{*}$ & $70 / 88(79.5 \%)$ & $47 / 71(66.2 \%)$ & 0.058 \\
\hline Felt pain (mean, SD)† & $6.3(2.3)$ & $7.2(2.3)$ & $0.013^{*}$ & $5.8(2.4)$ & $7.0(2.1)$ & $0.022^{*}$ \\
\hline $\begin{array}{l}\text { Felt in control (mean, } \\
\text { SD) } \dagger\end{array}$ & $7.5(2.0)$ & $6.1(2.9)$ & $0.017^{*}$ & $7.8(1.8)$ & $7.1(2.1)$ & 0.266 \\
\hline \multicolumn{7}{|c|}{ 2. Receipt of professional support } \\
\hline $\begin{array}{l}\text { Midwife understood } \\
\text { my needs }\end{array}$ & $157 / 160(98.1 \%)$ & $131 / 135(97.0 \%)$ & 0.341 & $88 / 89$ (98.9\%) & $69 / 71(97.2 \%)$ & 0.433 \\
\hline Felt well cared for & 159/160 (99.4\%) & $131 / 135(97.0 \%)$ & 0.063 & $89 / 89(100.0 \%)$ & 70/71 (98.6\%) & 0.261 \\
\hline $\begin{array}{l}\text { Midwife devoted time } \\
\text { to birth partner }\end{array}$ & $157 / 160(98.1 \%)$ & $129 / 135(95.5 \%)$ & 0.120 & $88 / 89(98.9 \%)$ & $69 / 71(97.2 \%)$ & 0.433 \\
\hline $\begin{array}{l}\text { Midwife devoted time } \\
\text { to me }\end{array}$ & 159/160 (99.4\%) & $132 / 135(97.8 \%)$ & 0.123 & $89 / 89(100.0 \%)$ & 70/71 (98.6\%) & 0.261 \\
\hline $\begin{array}{l}\text { Midwife kept me } \\
\text { informed }\end{array}$ & $156 / 160(97.5 \%)$ & $132 / 135(97.8 \%)$ & 0.816 & $87 / 89$ (97.8\%) & $69 / 71(97.2 \%)$ & 0.819 \\
\hline
\end{tabular}

3. Perceived sense of safety

$\begin{array}{lllllll}\text { Positive memories } & 142 / 160(88.8 \%) & 98 / 135(72.6 \%) & <0.001^{\star \star} & 82 / 89(92.1 \%) & 60 / 71(84.5 \%) & 0.129 \\ \text { Negative memories } & 20 / 160(12.5 \%) & 36 / 135(26.7 \%) & 0.002^{\star \star} & 8 / 89(9.0 \%) & 12 / 71(16.9 \%) & 0.133 \\ \text { Felt scared } & 42 / 159(26.4 \%) & 70 / 135(51.9 \%) & <0.001^{* \star} & 22 / 88(25.0 \%) & 20 / 71(28.2 \%) & 0.652 \\ \text { Team in general } & 159 / 160(99.4 \%) & 132 / 135(97.8 \%) & 0.123 & 89 / 89(100.0 \%) & 70 / 71(98.3 \%) & 0.261 \\ \text { Felt secure (mean, } & 8.8(1.5) & 8.0(2.1) & 0.126 & 9.0(1.2) & 8.4(1.7) & 0.038^{\star} \\ \text { SD) } \dagger & & & & & \end{array}$

4. Participation/engagement

\begin{tabular}{lllllll} 
Freedom of movement & $153 / 160(95.6 \%)$ & $76 / 134(56.7 \%)$ & $<0.001^{\star \star}$ & $87 / 89(97.8 \%)$ & $66 / 71(93.0 \%)$ & 0.141 \\
$\begin{array}{l}\text { Had a say about birth } \\
\text { position }\end{array}$ & $150 / 159(94.3 \%)$ & $103 / 134(76.9 \%)$ & $<0.001^{\star \star}$ & $83 / 88(94.3 \%)$ & $67 / 71(94.4 \%)$ & 0.990 \\
Choice of pain relief & $156 / 159(98.1 \%)$ & $115 / 134(85.8 \%)$ & $<0.001^{\star \star}$ & $88 / 89(98.9 \%)$ & $68 / 70(97.1 \%)$ & 0.425 \\
\hline
\end{tabular}

${ }^{*} \mathrm{P}<0.05,{ }^{*} \mathrm{p}<0.01$.

†Visual Analogue Scale from 1 to 10 (1=low, 10=high).

$\ddagger$ Numbers and percentages are based on total numbers of women who returned questionnaires (missing cases were removed from individual questions/statements)

appropriate control group. Another strength was the careful subclassification of WI use into water for labour only and for birth, as outcomes for these different groups have been pooled in many published studies. Additional strengths include the subgroup analyses for nulliparous women which has important implications for future pregnancies and subsequent births. Incorporation of a qualitative component with the use of a validated CEQ also adds strength. This study demonstrates the power of a research framework in supporting change within the context of a traditional approach to maternity 
care provision and institutional resistance to what was perceived to be a risky choice for women.

The main limitations of the study are the small sample size and the fact that it is not an RCT. Several authors have estimated that for an RCT a sample size of up to 3500 participants would be required to evaluate rare perinatal outcomes. ${ }^{1023}$ A study of that size would require multicentre recruitment and considerable resources. The women in this study were self-selected and those who chose to use WI may have had a strong preference to avoid interventions, which may be a potential source of bias. We aimed to address the differences between study participant groups by conducting logistic regression analyses controlling for confounding factors. It would be helpful to provide a health economic analysis which we hope to do at a later date.

\section{Comparison with the existing literature}

The safety and efficacy of WI for labour has been well established in previous research studies. RCTs and observational studies have reported reduced use of regional analgesia, shortened labour duration, increased maternal satisfaction rates, with no adverse effects on maternal or neonatal outcomes. ${ }^{1024-26}$ The evidence to support birth in water is more limited and for this reason WB is more controversial. The authors of the latest Cochrane Systematic Review on WB concluded that overall there was no evidence of increased adverse effects to the neonate or mother from giving birth in water ${ }^{24}$ although they acknowledged that the evidence in the form of RCTs was limited.

\section{Epidural and mode of birth}

Women in our study who used WI reported feeling less pain, resulting in a lower rate of epidural analgesia, a finding that is consistent with other studies. ${ }^{1026-30}$ Immersion in warm water is thought to help relieve muscle spasm, decrease gravity and pressure on the abdominal muscles, and reduce strain on the pelvis. ${ }^{31}$ We also reported a lower rate of OVB and higher rate of SVB among the WI cohort, consistent with published literature. ${ }^{10}{ }^{26}$ Women using WI are more mobile and encouraged to adopt up-right positions during labour and birth, which is thought to enhance uterine perfusion, contraction effectiveness and fetal alignment within the pelvis. ${ }^{25} 3233$

\section{Perineal trauma}

The association between $\mathrm{WB}$ and perineal trauma is controversial. We found no difference in the incidence of perineal tears requiring suturing between women in the WI and standard care cohorts. Similarly, we found no difference in the incidence of OASI. On comparing $\mathrm{WB}$ and $\mathrm{WL}$, there was a lower incidence of perineal tears requiring sutures with WB and no difference in OASI. In keeping with our findings, two studies have reported less requirement for perineal suturing in women who had a WB, ${ }^{93}$ and others have shown no difference. ${ }^{34}$ It is postulated that the 'hands off' approach to WB and 'non directive' pushing has a positive effect on perineal outcomes. ${ }^{35}$ Also, warm water is thought to increase vasodilation and elasticity of the perineal muscles. ${ }^{36}$ The findings in relation to OASI are conflicting, with several observational studies showing no negative impact of $\mathrm{WB}^{10263738}$ and two retrospective studies reporting a higher incidence with a doubling of OASI in one study (2.5\% vs $1.2 \%) .{ }^{39}{ }^{40}$ Cortes $e t a l^{39}$ attributed the increase to difficulty visualising the perineum during WB and the 'hands off' approach used. Nulliparous women are at higher risk of perineal trauma and while our findings for perineal tears requiring suturing were reassuring, the number of OASI were small and a larger study would be required to exclude any clinically important differences.

\section{Postpartum haemorrhage}

Women in the WI cohort were more than twice as likely $(10.5 \%$ vs $3.7 \%)$ to have a PPH $(\geq 500 \mathrm{~mL})$ than those receiving standard care. This was, not related to WB per se where the incidence was lower than for WI for labour only. Women who choose WI often opt for physiological management of the third stage of labour, as was seen in our study, which may increase PPH rate. ${ }^{41}$ However, of the 20 women who had a PPH in the WI cohort, only two had physiological management of the third stage, the remaining 18 were actively managed. Of note, significantly more women in the WI cohort had a third stage of labour $>30$ min and a higher number of babies weighing $>4 \mathrm{kgs}$ at birth. Both of these are risk factors for $\mathrm{PPH}^{42}$ and may have contributed to an increased blood loss. In contrast, other studies have reported similar or less blood loss during WB. ${ }^{26} 3743$ However, it has been acknowledged that there is a paucity of research on management of the third stage of labour during $\mathrm{WB}^{2444}$ and therefore women should be advised of potential risks and benefits about third stage labour management during pool use.

\section{Adverse neonatal events}

Similar to other studies of WB, there were no serious adverse neonatal outcomes in our study and no difference in admissions to the NNU. ${ }^{7-10} 24$ No baby born in water displayed signs of water aspiration or infection, which have been cited as concerns by others. ${ }^{45-51}$ There were two incidences of cord avulsion 'snaps'; one following a WB and one in the WL group; neither baby suffered adverse consequences. To minimise neonatal clinical risk, all women using the pool were carefully triaged, monitored closely, and were asked to exit the pool if concerns arose. To protect the 'diving reflex', that is, to ensure respiratory movements were inhibited, particular attention was given to maintaining appropriate water temperature, employing a 'hands off' birth technique and ensuring the woman kept the lower half of her body under water during birth. ${ }^{52}$ Exclusive breastfeeding rates were significantly higher in the WI and WB cohorts, compared with women receiving standard care. Direct skin-to-skin contact and zero separation between mother 
and baby are aspects of routine WB care, resulting in early initiation breastfeeding. ${ }^{31} 53$

\section{Birth experience}

Women in the WI cohort rated their birth experiences more highly than women in the standard care cohort. Several previous studies report increased levels of personal autonomy and greater satisfaction rates in women using WI. ${ }^{9} 252954$ Compared with women receiving standard care, women in the WI cohort reported feeling in control with regard to their choice of pain relief, their mobility and birth position. A recent systematic qualitative review reported that what mattered most for women when giving birth was a positive outcome, including giving birth to a healthy baby in a clinically and psychologically safe environment and with a sense of personal achievement and control. ${ }^{55}$ The results of our study show that WI, and in particular WB, fulfils these needs.

\section{Clinical service implications}

Maternity care in the Ireland is undergoing change at national level, with health policy placing greater emphasis on individualised and physiological approaches to childbirth. ${ }^{3}$ This study is, therefore, timely, as the findings demonstrate that with appropriate selection criteria and close attention to midwifery expertise, WI for labour and birth is safe and a desirable option for low-risk women. The concern regarding higher rates of OASI in WB, which was the underlying premise for this study, was not substantiated. It is hoped that the public demand for WB will continue to be supported at the Coombe Hospital and that other maternity units nationally will introduce similar services for women seeking physiological low intervention births. This study will inform healthcare providers and women who choose WI for birth.

\section{CONCLUSION}

Women choosing WI for labour or birth were no more likely to experience adverse birth outcomes than women receiving standard care. WI appears to be a safe alternative for low-risk women and is rated highly by women in terms of a positive birth experience.

Acknowledgements We would like to thank the women who participated in this study and the midwives and healthcare professionals who provided care and supported the objectives of the study. We would like to acknowledge Ms P Hughes, Ms B Flanagan, Dr E Burns, Ms K Robinson, Ms D Garland, Ms A Maclntyre, the Hospital Water Immersion interdisciplinary working group; Professor S Sheehan, Prof C Fitzpatrick, Dr B Byrne, Dr J Miletin and Dr M Carey, and the Hospital Board of Management. Sincere thanks to Ms Anna Dencker for granting permission to utilise her Childbirth Experience Questionnaire.

Contributors DJM (guarantor) had the original idea for the study and together with $\mathrm{PB}, \mathrm{RB}$ and $\mathrm{AF}$ designed the study. $\mathrm{PB}$ was responsible for piloting the project, recruiting patients and collecting the data. PB, LEM and DJM were responsible for data cleaning, recoding and performing the analyses. PB, LEM and DJM drafted the manuscript and all authors contributed to the final manuscript.

Funding Funding was received by the Nursing and Midwifery Practice Development Unit to support Paula Barry in her role as midwifery researcher. Grant 2016:01

Competing interests None declared.
Patient and public involvement Patients and/or the public were involved in the design, or conduct, or reporting, or dissemination plans of this research. Refer to the Methods section for further details.

Patient consent for publication Not required.

Ethics approval Ethical approval was granted by the Hospitals Research Ethics Committee in October 2015 (Study No 33-2015).

Provenance and peer review Not commissioned; externally peer reviewed.

Data availability statement All data relevant to the study are included in the article or uploaded as online supplemental information.

Open access This is an open access article distributed in accordance with the Creative Commons Attribution Non Commercial (CC BY-NC 4.0) license, which permits others to distribute, remix, adapt, build upon this work non-commercially, and license their derivative works on different terms, provided the original work is properly cited, appropriate credit is given, any changes made indicated, and the use is non-commercial. See: http://creativecommons.org/licenses/by-nc/4.0/.

ORCID iD

Deirdre J Murphy http://orcid.org/0000-0001-6074-6718

\section{REFERENCES}

1 MacKenzie Bryers $\mathrm{H}$, van Teijlingen $\mathrm{E}$. Risk, theory, social and medical models: a critical analysis of the concept of risk in maternity care. Midwifery 2010;26:488-96.

2 Renfrew MJ, Homer CSE, Downe S, et al. Midwifery is a vital solution to the challenges of providing high-quality maternal and new-born care for all women and new-born infants, in all countries. Midwifery: An executive summary for the Lancet's series. Lancet 2014 https:// www.thelancet.com/pb/assets/raw/Lancet/stories/series/midwifery/ midwifery_exec_summ.pdf

3 Department of Health. Creating a better future together. National maternity strategy 2016-2026. Dublin, Ireland: Department of Health, 2016.

4 Begley C, Devane D, Clarke M. Report of the MidU study. An evaluation of midwifery-led care in HSE North eastern area. HSE and University of Dublin, Trinity College school of nursing and midwifery 2009 https://nursing-midwifery.tcd.ie/assets/publications/pdf/midureport.pdf

5 Birthplace in England Collaborative Group, Brocklehurst P, Hardy P, et al. Perinatal and maternal outcomes by planned place of birth for healthy women with low risk pregnancies: the birthplace in England national prospective cohort study. BMJ 2011;343:d7400.

6 Sandall J, Soltani H, Gates S, et al. Midwife-led continuity models versus other models of care for childbearing women. Cochrane Database Syst Rev 2016;4:CD004667.

7 Taylor H, Kleine I, Bewley S, et al. Neonatal outcomes of waterbirth: a systematic review and meta-analysis. Arch Dis Child Fetal Neonatal Ed 2016;101:F357-65.

8 Bovbjerg ML, Cheyney M, Everson C. Maternal and newborn outcomes following waterbirth: the midwives alliance of North America statistics project, 2004 to 2009 cohort. J Midwifery Womens Health 2016;61:11-20.

9 Nutter E, Meyer S, Shaw-Battista J, et al. Waterbirth: an integrative analysis of peer-reviewed literature. J Midwifery Womens Health 2014;59:286-319.

10 Burns EE, Boulton MG, Cluett E, et al. Characteristics, interventions, and outcomes of women who used a birthing pool: a prospective observational study. Birth 2012;39:192-202.

11 Health Information and Quality Authority. National standards for safer better maternity services. Dublin: Health Information and Quality Authority, 2016.

12 ten Hoope-Bender P, de Bernis L, Campbell J, et al. Improvement of maternal and newborn health through midwifery. Lancet 2014;384:1226-35.

13 Smith V, Daly D, Lundgren I, et al. Salutogenically focused outcomes in systematic reviews of intrapartum interventions: a systematic review of systematic reviews. Midwifery 2014;30:e151-6.

14 World Health Organisation. Maternal, new-born, child and adolescent health. The case for midwifery. midwives voices, midwives realities report. Geneva: World Health Organisation, 2016. https://www.who. int/maternal_child_adolescent/documents/midwives-voices-realities/ en/

15 Committee on Obstetric Practice. Committee opinion no. 687: approaches to limit intervention during labor and birth. Obstet Gynecol 2017;129:e20-8. 
16 Klynveld, Peat, Marwick, Goerdeler (KPMG). Independent review of maternity and gynaecology services in the greater Dublin area. Dublin: Health Services Executive, 2008. http://thenewchildrensh ospital.ie/wpcontent/uploads/2011/08/Independent_Review ofMaternity_and_Gynaecology_Services_in_the_greater_Dublin_ area_.pdf

17 Kennedy P. Healthcare reform: maternity service provision in Ireland. Health Policy 2010;97:145-51.

18 Doherty A. HSE Communication from Director of National Hospital's Office regarding: Water Birthing Ban. Dublin, Ireland: Health Service Executive, 2009.

19 Dencker A, Taft C, Bergqvist L, et al. Childbirth experience questionnaire (CEQ): development and evaluation of a multidimensional instrument. BMC Pregnancy Childbirth 2010;10:81.

20 IBM Corp. IBM SPSS statistics for windows, version 24.0. Armonk, NY: IBM Corp, 2018. https://www01.ibm.com/support/docview.wss? uid=swg21476197

21 Sheehan S. Coombe Women \& Infants University Hospital Annual Report. Dublin: CWIUH, 2018.

22 Health Service Executive. Irish maternity indicator system national report 2018. Dublin, Ireland: Health Service Executive, 2018. https:// www.lenus.ie/bitstream/handle/10147/624770/IMIS\%20National\% 20Report\%202018.pdf?sequence $=1$ \&isAllowed $=y$

23 Davies MW. Water births and the research required to assess the benefits versus the harms. J Paediatr Child Health 2012;48:726-9.

24 Cluett ER, Burns E, Cuthbert A, et al. Immersion in water during labour and birth. Cochrane Database Syst Rev 2018;20:CD000111.

25 Shaw-Battista J. Systematic review of hydrotherapy research: does a warm Bath in labor promote normal physiologic childbirth? J Perinat Neonatal Nurs 2017;31:303-16.

26 Henderson J, Burns EE, Regalia AL, et al. Labouring women who used a birthing pool in obstetric units in Italy: prospective observational study. BMC Pregnancy Childbirth 2014;14:10.

27 Mollamahmutoğlu L, Moraloğlu O, Ozyer S, et al. The effects of immersion in water on labor, birth and newborn and comparison with epidural analgesia and conventional vaginal delivery. J Turk Ger Gynecol Assoc 2012;13:45-9.

28 Torkamani SA, Kangani F, Janani F. The effects of delivery in water on duration of delivery and pain compared with normal delivery. Pakistani Journal of Medical Science 2010;26:551-5.

29 Ulfsdottir H, Saltvedt S, Georgsson S. Waterbirth in Sweden - a comparative study. Acta Obstet Gynecol Scand 2018;97:341-8.

30 Geissbuehler V, Stein S, Eberhard J. Waterbirths compared with landbirths: an observational study of nine years. J Perinat Med 2004;32:308-14.

31 Garland D. Theories of hydrotherapy in labour. In: Garland D, ed. Revisiting Waterbirth; an attitude to care. London, UK: Palgrave, 2017: 64-78.

32 Gupta JK, Sood A, Hofmeyr GJ, et al. Position in the second stage of labour for women without epidural anaesthesia. Cochrane Database Syst Rev 2017;90:CD002006.

33 Gayiti M-R-Y, Li X-Y, Zulifeiya AK, et al. Comparison of the effects of water and traditional delivery on birthing women and newborns. Eur Rev Med Pharmacol Sci 2015;19:1554-8.

34 Smith LA, Price N, Simonite V, et al. Incidence of and risk factors for perineal trauma: a prospective observational study. BMC Pregnancy Childbirth 2013;13:59.
35 Garland D. Robust clinical care. In: Garland D, ed. Revisiting Waterbirth; an attitude to care. London, UK: Palgrave, 2017: 95-132.

36 Aasheim V, Nilsen ABV, Reinar LM, et al. Perineal techniques during the second stage of labour for reducing perineal trauma. Cochrane Database Syst Rev 2017;6:CD006672.

37 Menakaya U, Albayati S, Vella $\mathrm{E}$, et al. A retrospective comparison of water birth and conventional vaginal birth among women deemed to be low risk in a secondary level hospital in Australia. Women Birth 2013;26:114-8.

38 Dahlen HG, Dowling H, Tracy M, et al. Maternal and perinatal outcomes amongst low risk women giving birth in water compared to six birth positions on land. A descriptive cross sectional study in a birth centre over 12 years. Midwifery 2013;29:759-64.

39 Cortes E, Basra R, Kelleher CJ. Waterbirth and pelvic floor injury: a retrospective study and postal survey using ICIQ modular long form questionnaires. Eur J Obstet Gynecol Reprod Biol 2011;155:27-30.

40 McPherson KC, Beggs AD, Sultan AH, et al. Can the risk of obstetric anal sphincter injuries (OASIS) be predicted using a risk-scoring system? BMC Res Notes 2014;7:471.

41 Begley CM, Gyte GM, Devane D, et al. Active versus expectant management for women in the third stage of labour. Cochrane Database Syst Rev 2019;2:CD007412.

42 Mavrides E, Allard S, Chandraharan E, et al. Prevention and management of postpartum haemorrhage. BJOG 2017;124:e106-49.

43 Lim KMX, Tong PSY, Chong Y-S. A comparative study between the pioneer cohort of waterbirths and conventional vaginal deliveries in an obstetrician-led unit in Singapore. Taiwan J Obstet Gynecol 2016;55:363-7.

44 Dekker R. The evidence on waterbirth, 2018. Available: http:// evidencebasedbirth.com/waterbirth [Accessed 10 Nov 2019].

45 American College of Obstetricians and Gynecologists' Committee on Obstetric Practice. Committee opinion no. 679: immersion in water during labor and delivery. Obstet Gynecol 2016;128:e231-6.

46 Gilbert RE, Tookey PA. Perinatal mortality and morbidity among babies delivered in water: surveillance study and postal survey. BMJ 1999;319:483-7.

47 Mammas IN, Thiagarajan P. Water aspiration syndrome at birth report of two cases. J Matern Fetal Neonatal Med 2009;22:365-7.

48 Kassim Z, Sellars M, Greenough A. Underwater birth and neonatal respiratory distress. BMJ 2005;330:1071-2.

49 Nguyen S, Kuschel C, Teele R, et al. Water birth--a near-drowning experience. Pediatrics 2002;110:411-3.

50 Franzin L, Cabodi D, Scolfaro C, et al. Microbiological investigations on a nosocomial case of Legionella pneumophila pneumonia associated with water birth and review of neonatal cases. Infez Med 2004;12:69-75.

51 Byard RW, Zuccollo JM. Forensic issues in cases of water birth fatalities. Am J Forensic Med Pathol 2010;31:258-60.

52 Garland D. Breathing. In: Garland D, ed. Revisiting Waterbirth; an attitude to care. London, UK: Palgrave, 2017: 136-63.

53 Harper B. Birth, Bath, and beyond: the science and safety of water immersion during labor and birth. J Perinat Educ 2014;23:124-34.

54 Clews C, Church S, Ekberg M. Women and waterbirth: a systematic meta-synthesis of qualitative studies. Women Birth. In Press 2020;33:566-73.

55 Downe S, Finlayson K, Oladapo OT, et al. Correction: what matters to women during childbirth: a systematic qualitative review. PLoS One 2018;13:e0197791. 